\title{
Exploring pregnant women interest and anxiety to use the Internet and their perception and trust toward online information
}

\section{Leila Ahmadian}

Kerman University of Medical Sciences

Reza Khajouei ( $\nabla$ r.khajouei@yahoo.com )

Kerman University of Medical Sciences

\section{Sudabeh Kamali}

Kerman University of Medical Sciences

\section{Moghaddameh Mirzaee}

Graduate University of Advanced Technology

Research article

Keywords: Interest, Internet, Internet anxiety, Pregnant woman, Reliability

Posted Date: September 27th, 2019

DOl: https://doi.org/10.21203/rs.2.15291/v1

License: (c) (i) This work is licensed under a Creative Commons Attribution 4.0 International License. Read Full License 


\section{Abstract}

Background The Internet often represents a source of accessible information. The aim of this study was to examine pregnant women's interest and anxiety when they use the Internet and also to determine the criteria by which they evaluated the correctness and reliability of the information on the Internet.

Methods A descriptive study was conducted between April and July 2015. The pregnant women at the offices of obstetricians/gynecologists were invited to participate in the study by filling out a questionnaire.

Results Of the 450 distributed questionnaires, 420 were completed and analyzed. The mean of interest and anxiety scores respectively was 12.21 and 6.69 out of 20 . The most important criteria for judging the reliability and trustworthiness of a website were whether its information is continuously updated (69.2\%), or it is recommended by a doctor, nurse or other health professionals (63.1\%).

Conclusions : Since the interest to a website lowers the anxiety of pregnant women to use it, it is recommended to consider pregnant women's preferences and needs and follow user-centered approaches when designing websites. Medical content of the websites also should be carefully reviewed by a multidisciplinary board of medical specialists for the correctness and reliability of the information.

\section{Background}

In the last decades Internet use has become widespread and the number of Internet users has increased. Many people are using it to find health information by searching specific websites and forums, consulting online specialists (1) and participating in discussion groups (2). Also some patients get information to prepare for appointment or surgery by looking up the diagnoses, prescriptions, procedures, or treatments on the Internet (3). Many practitioners and researchers believe that people, who are better informed, are also better able to reduce their personal anxieties about understanding what is going to happen and to participate in decisions about their own health care (4). Pregnancy is a time when many women feel isolated and confused (4) and it often causes anxiety and fear (1). During this period the need for information increases (5). Since, health information can reduce distress and anxiety (6) of the pregnant women and their families in this period they used many sources to obtain information.

With the increase use of the Internet as an information media and the fast growing online sources of information a wide range of health-related issues, including pregnancy and childbirth (4), are expected to present on the Internet (5). Studies have demonstrated that pregnant women are using the Internet to seek pregnancy-related information (5, 8-19). The Internet often offers a never-ending source of information and support (4). It can be the source of most current information (3) and represents a source of cheap and easily accessible information (1). So it may be an ideal delivery mechanism for pregnant women (20). However, it is debatable whether all information on the Internet is correct and reliable $(5,21)$. Given that, pregnancy-related websites are more and more available on the Internet (12) and many pregnant women get the health information about pregnancy and childbirth from the Internet and they 
may end up with wrong information if they use search engines without looking at the reliability of the site or whether it has been written by an expert (5); determining the reliability of information on the Internet has become increasingly important. On the other hand, the Internet may cause anxiety in pregnant women (4).

The aim of this study was to examine pregnant women's interest and anxiety when they use the Internet to access the health information during pregnancy and also to determine the criteria which the pregnant women evaluated the correctness and reliability of the information on the Internet. This study was done to test the following research hypothesis:

- There is a significant relationship between interest and anxiety scores of pregnant women.

- There is a significant relationship between age, educational degree, and working status; and interest and anxiety scores of pregnant women.

\section{Methods}

We surveyed pregnant women in Kerman, the largest city in southeast of Iran. In 2016, the population of this city is around 3.165 million (22). Five thousand and four hundred and forty cases of birth are registered monthly in the whole of this province (23).

A sample of 384 pregnant women were selected using Cochran's sample size formula $(z=1.96, p=0.5, q$ $=0.5, d=0.05$ ). To reduce sampling error, the sample size was increased to 450 pregnant women. They were met in 40 out of 77 clinics and obstetricians/gynecologists' offices in Kerman. These clinics and offices were randomly selected from different geographic regions in this city. After receiving permission to do the survey from secretaries of offices and clinics, the research staff approached women when waiting for their appointments in the clinics and obstetricians/gynecologists' offices. After introducing the study objectives to them, and getting their verbal consent, they were asked to complete the questionnaire. To increase the response rate and to acknowledge the participation in the study, the researcher awarded a gift (a small pocket sized book) to participating pregnant women.

The questionnaire was constructed by review of the relevant literature $(5,7,9,11,13,15,20,24-33)$. The content validity of the questionnaire was obtained by asking opinion of four medical informaticians with background in medicine and health information management and an obstetrician/gynecologist. Then test-re-test method was applied to test the reliability of the questionnaire. The questionnaire was tested among 20 women who were not included in the study. All women could understand and complete the questions easily, so no changes were needed. The 2-week test-retest correlation for the questionnaire was 0.96 .

The questionnaire consisted of four sections and 32 questions. The first section contained 7 questions and captured demographic and pregnancy-related data and the participants' Internet use to search information about pregnancy and childbirth. The second section contained 6 questions and sought data 
on the respondents' interest to use the Internet to access health information during pregnancy. In the third section, 6 questions focused on participants' anxiety when they use the Internet. A five-point Likert scale with anchors (1) very little to (5) very much was used to assess the interest and anxiety of participants when using the Internet. The fourth section were determined the criteria by which the pregnant women evaluated the correctness and reliability of the information on the Internet. It included 13 closed questions with predetermined answers. Interest and anxiety scores, for better interpretation of results, were assessed with a numeric scale from 0 to 20 , according to the below formula; we considered the range 0 5 as 'very low', 6-10 as 'low', 11-15 as 'moderate' and 16-20 as 'high'.

$$
\mathrm{Y}=\left(\left(\frac{(\text { Old value }- \text { Old Min }) *(\text { New Max }- \text { New Min })}{(\text { Old Max }- \text { Old Min })}\right)\right)+\text { New Min }
$$

All statistical analyses were performed with SPSS (IBM SPSS Statistic 19). Descriptive statistics were calculated in terms of percentage, mean, and frequency. In order to investigate the relationship between interest and anxiety of the participants when using the Internet, Pearson correlation coefficient was used. Also, in order to examine the relationship among the participants' demographic variables (age, education and working status) with interest and anxiety, Kruskal Wallis test was used. Significance levels were set at $p=0.05$.

\section{Results}

Of the 450 distributed questionnaires, 420 were completed and returned, yielding an overall response rate of $93 \%$. Participants were between the ages of 18-44 (mean $27.51 \pm 4.7$ ). Most of them were in their third trimester of pregnancy $(n=176,41.9 \%)$ and were experiencing their first pregnancy $(n=227,54.2 \%)$. Also more than half of them were unemployed $(n=247,58.8 \%)$ (Table 1$)$.

Table 1. Demographic and pregnancy characteristics of respondents

\section{[Please, insert Table 1 about here]}

Most of the participants had a bachelor degree $(n=232,55.2 \%)$ Other demographic and pregnancy characteristics of the sample are listed in Table 1. A majority of the pregnant women $(n=366,87.7 \%)$ reported using the Internet for pregnancy and childbirth related information (Table 1).

The pregnant women were asked to determine their interest and anxiety when they use the Internet to search health information during pregnancy, using a scale from 1 to 5 . The five-point scale was collapsed into three points where 1-2 were categorized as low interest/anxiety, 3 as medium interest/anxiety and 4-5 as high interest/anxiety. The results are shown in Fig. 1 and Fig. 2. 


\section{[Please, insert Fig. 1 about here]}

\section{Fig. 1. Pregnant women's interest to use the Internet for searching health information}

\section{[Please, insert Fig. 2 about here]}

\section{Fig. 2. Pregnant women's anxiety when they use the Internet to access the health information}

Also the mean score of interest for the Internet use was 12.21, i.e. the interest of pregnant women was assessed as moderate and the mean score of participants' anxiety when using the Internet was 6.69 that was assessed as low.

The results of Pearson correlation coefficient revealed that there was a significant negative correlation between interest and anxiety scores $(p=<0.0001, r=0.189)$. This means that the higher the interest to use the Internet, the lower anxiety is. Also, Kruskal Wallis test showed a statistically significant relationship between educational degree and interest score $(p=<0.0001)$. There was no significant relationship between interest and anxiety scores with other demographic variables.

The results showed that only $8.8 \%$ of the mothers had confidence to all of provided information on the Internet and more than two-thirds of them (67.4\%) checked the accuracy of received information from the Internet with their doctors or other health care providers. About one third of them $(33.8 \%)$ only used the trusted sites.

The women were asked to select criteria by which they judge the correctness and reliability of the health information provided on the Internet. The results are presented in Table 2. The most important criteria for judging the reliability and trustworthiness of a website were whether it's their information is continuously updated (70.5\%), it is recommended by a doctor, nurse or other health professionals $(64.7 \%)$, the information is added by an expert (54.8\%) and the information is in accordance with facts from other sources $(52.9 \%)$.

Table 2. The criteria by which the pregnant women judged the correctness and reliability of the web-based health information

\section{[Please, insert Table 2 about here]}

\section{Discussion And Conclusions}


Although there are scientific websites presenting pregnancy and childbirth-related information, this research showed that pregnant women are moderately receptive about getting this information from the Internet. The results showed that some of them could not trust the information and use it with anxiety. About one third of the pregnant women had a high concern about violation of the privacy when using the Internet. Most participants were controlled the accuracy of received information from the Internet with their doctor or other health care providers. Updating the information on the Internet was the most important criteria for women to judge about reliability and correctness of the website. More than sixty present of the women reported that the reliable websites are those recommended by health care professionals. Other studies showed that most important criteria for judging the quality of web-based health information were the similarity of the provided information with the facts from other sources, the source of the information was given $(9,13)$ and the information on the internet was written by an expert (5). In the current study, these criteria were also reported by about $38 \%$ to $54 \%$ of the participants.

The results showed that some of the participants had anxiety when using the Internet, this results was not consistent with the results of another study showed that most participants do not have any anxiety in relation to the Internet (29). This may because of the differences in the study population and the purpose of the Internet use. The population of the study done by Joiner et al. (2007) (29) were both female and male university students. Therefore, the focus of these two study populations for the Internet use may differ. Studies indicated that women had higher anxiety than men when using the Internet $(24,26,29,33$, 34). By providing appropriate resources and fostering a supportive environment, users could reduce the Internet anxiety (30) and thus they can benefit from the advantages of this technology. The Internet may evoke anxiety because it requires users to learn new terminology and understand new applications that may seem strange to them (30).

More than half of the pregnant women in this survey had interest in using the Internet for health-related information. This results are in line with the results of the previous researches $(18,19,21,25,28,32,35$, 36). Access to information, demographics characteristics and, particularly, motivational factors all can influence patients' interest for using the Internet as a health information resource (28). The findings of the current study are similar to the finding of another study (29) that has shown psychological factor, namely Internet anxiety and educational degree, were related to interest in using the Internet. Proposals to encourage more widespread use of health information on the Internet, need to take account of this factors influencing the Internet use. Professional layout of the designed website is applied as a criterion for judgment about the website reliability by a few numbers of the participants. Therefore, following usercentered approaches, when designing websites, can attract the users' attention and increase their interest in using this technology (37).

This study has a limitation. This study was done on the pregnant women living in urban areas. The results might not be completely generalizable to other pregnant women. Hence the future studies should include women from different living areas. However, to our knowledge this study is the only study that explores the pregnant women interest and anxiety toward the Internet. 
As there are a vast number of possible websites pregnant women could search, a health professional's recommendation is helpful in choosing the right one. Health professionals and midwives are expected to support pregnant women in retrieval and interpretation of web-based health information and provide relevant, up-to-date information that meets the needs of them in pregnancy and childbirth. Also they should have ability to clarify any questions or concerns that arise from that use. In addition, health professionals and midwives need to possess Internet skills so that they can assist pregnant women to access reliable websites, to direct them to high quality websites that consistent with best practices and to make fully informed choices in relation to pregnancy and birth plan. In addition, government should make a significant investment in the technological infrastructure required for this electronic transaction.

\section{Declarations}

\section{Conflict of Interest}

Authors declare that they have no conflict of interest.

\section{Authors' contributions}

L. Ahmadian, R. Khajouei, and S. Kamali contributed to the conception and design of the study, acquisition and interpretation of the data, and drafting the paper. M. Mirzaee was primarily responsible for the statistical analysis of the data. All 4 authors read and approved the final version of the manuscript submitted.

\section{Ethical Approval}

Research ethics committee of Kerman University of Medical Sciences approved this study (IR.KMU.REC.2015.92). To collect the data, first one of the authors explain the study objectives to the participants, and after she got their verbal consent, she asked them to complete the questionnaire.

\section{Funding Sources}

This research did not receive any specific grant from funding agencies in the public, commercial, or notfor-profit sectors.

\section{Acknowledgements}

Authors would like to express gratitude to the pregnant women who participated in this study and took time to respond to the survey. Also they would like to thank all of the obstetricians/gynecologists who allowed us to distribute the questionnaires at their offices and clinics. 


\section{References}

1.De Santis M, De Luca C, Quattrocchi T, Visconti D, Cesari E, Mappa I, Nobili E, Spagnuolo T, Caruso A. Use of the Internet by women seeking information about potentially teratogenic agents. European Journal of obstetrics \& gynecology and reproductive biology. 2010 Aug 1;151(2):154-7.

2.Bessell TL, McDonald S, Silagy CA, Anderson JN, Hiller JE, Sansom LN. Do Internet interventions for consumers cause more harm than good? A systematic review. Health Expectations. 2002 Mar;5(1):2837.

3.Dickerson SS. Women's use of the Internet: what nurses need to know. Journal of Obstetric, Gynecologic \& Neonatal Nursing. 2006 Jan 1;35(1):151-6.

4.Lagan BM, Sinclair M, Kernohan WG. Pregnant women's use of the internet: a review of published and unpublished evidence. Evidence Based Midwifery. 2006;4(1):17-23.

5.Kavlak O, Atan ŞÜ, Güleç D, Öztürk R, Atay N. Pregnant women's use of the internet in relation to their pregnancy in Izmir, Turkey. Informatics for health and social care. 2012 Dec 1;37(4):253-63.

6.Michie, S., Rosebert, C., Heaversedge, J., Madden, S., Parbhoo, S., 1996. The effects of different kinds of information on women attending an out-patient breast clinic. Psychology, Health \& Medicine 1(3), 285296.

7.Lagan, B. M., Sinclair, M., Kernohan, W. G., 2011. A web-based survey of midwives' perceptions of women using the Internet in pregnancy: a global phenomenon. Midwifery 27(2), 273-281.

8.Declercq, E. R., Sakala, C., Corry, M. P., Applebaum, S., 2006. Listening to mothers II: Report of the second national US survey of women's childbearing experiences. The Journal of Perinatal Education 16(4), 9-14.

9.Larsson M. A descriptive study of the use of the Internet by women seeking pregnancy-related information. Midwifery. 2009 Feb 1;25(1):14-20.

10.Bakhireva LN, Young BN, Dalen J, Phelan ST, Rayburn WF. Patient utilization of information sources about safety of medications during pregnancy. The Journal of reproductive medicine. 2011;56(78):339-43.

11.Lagan BM, Sinclair M, George Kernohan W. Internet use in pregnancy informs women's decision making: a web-based survey. Birth. 2010 Jun;37(2):106-15.

12.Bert F, Gualano MR, Brusaferro S, De Vito E, De Waure C, La Torre G, Manzoli L, Messina G, Todros T, Torregrossa MV, Siliquini R. Pregnancy e-health: a multicenter Italian cross-sectional study on Internet use and decision-making among pregnant women. J Epidemiol Community Health. 2013 Dec 1;67(12):10138. 
13.Gao LL, Larsson M, Luo SY. Internet use by Chinese women seeking pregnancy-related information. Midwifery. 2013 Jul 1;29(7):730-5.

14. Huberty J, Dinkel D, Beets MW, Coleman J. Describing the use of the internet for health, physical activity, and nutrition information in pregnant women. Maternal and child health journal. 2013 Oct 1;17(8):1363-72.

15.Rodger D, Skuse A, Wilmore M, Humphreys S, Dalton J, Flabouris M, Clifton VL. Pregnant women's use of information and communications technologies to access pregnancy-related health information in South Australia. Australian journal of primary health. 2013 Dec 9;19(4):308-12.

16.Lynch C, Nikolova G. Do mothers use the internet for pregnancy related information and does it affect their decisions during the pregnancy? A literature review. MIDIRS Midwifery Digest. 2015;25(1):21-6.

17.Sayakhot $\mathrm{P}$, Carolan-Olah $\mathrm{M}$. Internet use by pregnant women seeking pregnancy-related information: a systematic review. BMC pregnancy and childbirth. 2016 Dec;16(1):65.

18.Bjelke M, Martinsson AK, Lendahls L, Oscarsson M. Using the Internet as a source of information during pregnancy-A descriptive cross-sectional study in Sweden. Midwifery. 2016 Sep 1;40:187-91.

19.Sinclair M, Lagan BM, Dolk H, McCullough JE. An assessment of pregnant women's knowledge and use of the Internet for medication safety information and purchase. Journal of advanced nursing. 2018 Jan;74(1):137-47.

20.Waring ME, Simas TA, Xiao RS, Lombardini LM, Allison JJ, Rosal MC, Pagoto SL. Pregnant women's interest in a website or mobile application for healthy gestational weight gain. Sexual \& Reproductive Healthcare. 2014 Dec 1;5(4):182-4.

21.De Boer MJ, Versteegen GJ, Van Wijhe M. Patients' use of the Internet for pain-related medical information. Patient education and counseling. 2007 Sep 1;68(1):86-97.

22.SCI (Statistical Center of Iran). Selected Findings of the 2016 National Population and Housing Census [Internet]. 2018 [cited 2019 Jan 23] Available from:https://www.amar.org.ir/english/Statistics-byTopic/Population\#2224493-releases/

23.Young Journalist Club. Birth of 48 thousand and 963 infants in Kerman [Internet]. 2015 [cited 2015 June 10]. Available from: http://www.yjc.ir/

24.Chua SL, Chen DT, Wong AF. Computer anxiety and its correlates: a meta-analysis. Computers in human behavior. 1999 Sep 1;15(5):609-23.

25.Monnier J, Laken M, Carter CL. Patient and caregiver interest in internet-based cancer services. Cancer Practice. 2002 Nov;10(6):305-10. 
26. Chou C. Incidences and correlates of Internet anxiety among high school teachers in Taiwan. Computers in Human Behavior. 2003 Nov 1;19(6):731-49.

27.Macaulay M. The effects of web-assisted learning on students' anxiety. Journal of Educational Computing Research. 2003 Apr;28(3):221-30.

28.Mead N, Varnam R, Rogers A, Roland M. What predicts patients' interest in the Internet as a health resource in primary care in England?. Journal of health services research \& policy. 2003 Jan;8(1):33-9.

29.Joiner R, Brosnan M, Duffield J, Gavin J, Maras P. The relationship between Internet identification, Internet anxiety and Internet use. Computers in Human Behavior. 2007 May 1;23(3):1408-20.

30.Thatcher JB, Loughry ML, Lim J, McKnight DH. Internet anxiety: An empirical study of the effects of personality, beliefs, and social support. Information \& Management. 2007 Jun 1;44(4):353-63.

31.Kommalage M. Use of the internet by patients attending specialist clinics in Sri Lanka: a cross sectional study. BMC medical informatics and decision making. 2009 Dec;9(1):12.

32.Quin J, Stams V, Phelps B, Boley T, Hazelrigg S. Interest in internet lung cancer support among rural cardiothoracic patients. Journal of Surgical Research. 2010 May 1;160(1):35-9.

33.Ekizoglu N, Ozcinar Z. A study of developing an anxiety scale towards the internet. Procedia-Social and Behavioral Sciences. 2011 Jan 1;15:3902-11.

34.Sun S. An examination of disposition, motivation, and involvement in the new technology context computers in human behavior. Computers in Human Behavior. 2008 Sep 17;24(6):2723-40.

35.Salo D, Perez C, Lavery R, Malankar A, Borenstein M, Bernstein S. Patient education and the Internet: do patients want us to provide them with medical web sites to learn more about their medical problems? The Journal of emergency medicine. 2004 Apr 1;26(3):293-300.

36.Rozenfeld Y, Johnson T, Klug C. Assessing interest in an osteoporosis website: a survey among women eligible for osteoporosis screening. Osteoporosis international. $2010 \mathrm{Jul}$ 1;21(7):1197-204.

37.Nabovati E, Vakili-Arki H, Eslami S, Khajouei R. Usability evaluation of Laboratory and Radiology Information Systems integrated into a hospital information system. Journal of medical systems. 2014 Apr 1;38(4):35.

\section{Tables}

Table1. Demographic and pregnancy characteristics of respondents $(n=420)$ 


\begin{tabular}{|c|c|}
\hline Demographic information & n (\%) \\
\hline \multicolumn{2}{|l|}{ Age group $(n=417)$} \\
\hline$<=20$ years & $24(5.8)$ \\
\hline $21-25$ years & $137(32.9)$ \\
\hline 26-30 years & $152(36.5)$ \\
\hline 31-35 years & $73(17.4)$ \\
\hline$>35$ years & $31(7.4)$ \\
\hline \multicolumn{2}{|l|}{ Educational degree $(n=420)$} \\
\hline Secondary/high school & $56(13.4)$ \\
\hline Associate degree & $86(20.5)$ \\
\hline Bachelor degree & $232(55.2)$ \\
\hline Master degree or higher & $46(10.9)$ \\
\hline \multicolumn{2}{|l|}{ Working status $(n=420)$} \\
\hline Unemployed & 248( 59 \\
\hline University student & $53(12.6)$ \\
\hline Employed & $119(28.4)$ \\
\hline \multicolumn{2}{|c|}{ Number of pregnancy $(n=419)$} \\
\hline 1 & $227(54.2)$ \\
\hline 2 & $138(32.9)$ \\
\hline 3 & $46(11)$ \\
\hline$\geq 4$ & $8(1.9)$ \\
\hline \multicolumn{2}{|l|}{ Number of children $(n=420)$} \\
\hline 0 & $240(57.1)$ \\
\hline 1 & $143(34)$ \\
\hline 2 & $34(8.2)$ \\
\hline 3 & $3(07)$ \\
\hline \multicolumn{2}{|l|}{ Gestational age $(n=420)$} \\
\hline First trimester & $109(26)$ \\
\hline Second trimester & $135(32.1)$ \\
\hline Third trimester & $176(41.9)$ \\
\hline
\end{tabular}

Table 2. The criteria by which the pregnant women judged the correctness and reliability of the web-based health information 


\begin{tabular}{lcc}
\hline Criteria & $\begin{array}{c}\text { Number } \\
\text { (n=420) }\end{array}$ \\
\hline 1. Continuous updating & 291 & 69.2 \\
2. Recommended by a doctor, nurse or other health care professionals & 268 & 63.1 \\
\hline 3. Written by an expert & 227 & 54 \\
\hline 4. Corresponds with facts from other sources & 210 & 50 \\
\hline 5. Recommended by media & 197 & 46.9 \\
\hline 6. Positive opinion of other users of information & 173 & 41.1 \\
\hline 7. Sources were given on the web page and references are provided & 159 & 37.9 \\
\hline 8. Run by governmental institutions & 149 & 35.5 \\
\hline 9. The number of visitors & 136 & 32.3 \\
\hline 10. Run by medical products manufacturing companies & 129 & 30.8 \\
\hline 11. Recommended by a friend, relatives or family & 128 & 30.5 \\
\hline 12. Professional layout & 98 & 23.3 \\
\hline
\end{tabular}

\section{Figures}

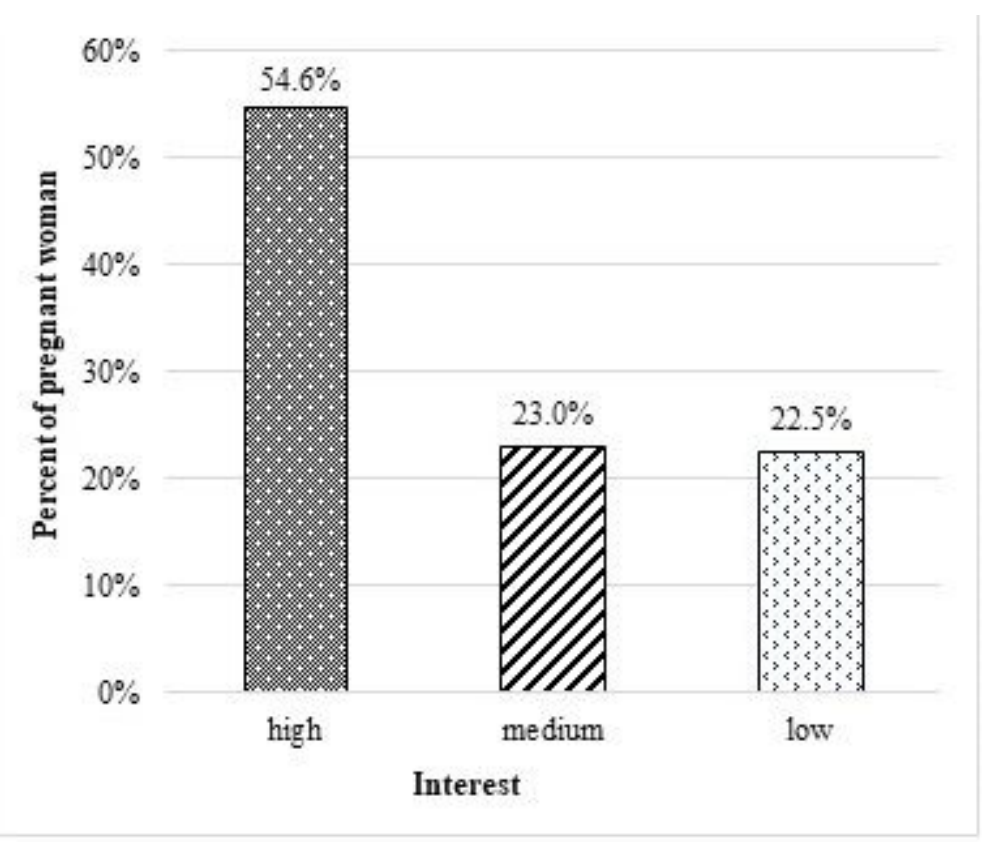

\section{Figure 1}

Pregnant women's interest to use the Internet for searching health information 


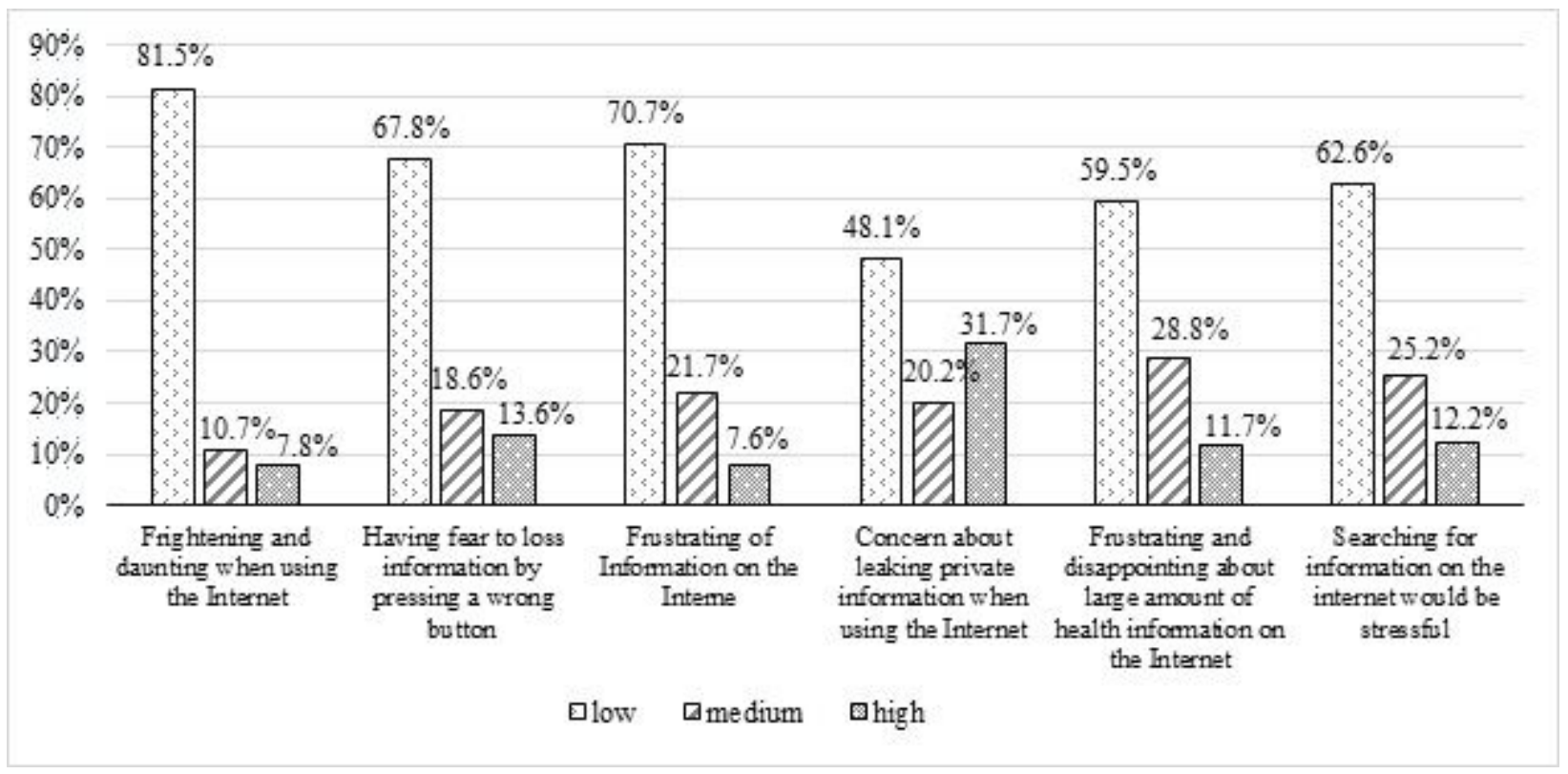

Figure 2

Pregnant women's anxiety when they use the Internet to access the health information 